\title{
Pipe Dreams? The Governance of Urban Water Supply in Informal Settlements, New Delhi
}

\author{
Suneetha Dasappa Kacker and Anuradha Joshi*
}

Abstract This article explores two trends which exemplify recent research and thinking in service delivery: first, understanding the role of small-scale informal providers and second, understanding the politics and governance of service provision. Drawing on field research on urban water in New Delhi, we show that while informal providers fill a gap left by the public utility, residents are captive consumers with limited ability to influence service quality or price. However, this low service level trap can be shifted; and the very seeds of change seem to lie in the evolving relationships between informal providers, residents of informal settlements, politicians and the water utility. The case highlights two factors that enabled the transition: (1) the nature of the service, particularly piped water systems, are more conducive to triggering collective action; and (2) rising political awareness and competition can enable community groups to break out of clientelistic relationships with local politicians.

\section{Introduction}

The New Delhi statement 'Some for All', following the Global Consultation on Safe Water and Sanitation (United Nations 1990: 4), noted the importance of people and institutions in its second principle, 'a changing role of government is envisaged from that of provider to promoter and facilitator. This will enable local public, private and community institutions to deliver better services'. The Dublin Statement (United Nations 1992: 1), two years later, underscored this by declaring in its second principle, that 'water development and management should be based on a participatory approach involving users, planners and policy makers at all levels'.

These principles are reflected in two trends which exemplify recent research and thinking in service delivery, including the provision of water in developing countries. First, there is greater attention being paid to non-state, or private providers, particularly small-scale informal private providers (Bakker 2008; Rose 2006; Batley 2006). In the water sector, such providers have been variously labelled as small-scale water sellers, informal operators, small water enterprises, water vendors and resellers
(Collignon and Vézina 2000; Sansom 2006; van Dijk 2008; McGranahan and Owen 2006). There is now a large and growing literature on the characteristics of such providers, and a lively debate about the need for incorporating them into public provision regimes in order to improve access and quality of drinking water for the poor. As part of this, there is also increasing interest in informal piped network providers due to their ability to invest, develop viable business models and scale-up operations (Conan 2005).

Second, and in parallel, there is a move towards looking beyond the technical aspects of service provision to the role of politics (Batley 2004). In the water sector, the shift is from issues of water provision, regulation, tariffs and quality, to the more political and governance aspects of provision, including policy influence through political participation, claim making and accountability (Chaplin 2011; Castro 2004). As the broader literature on service delivery points out, failures of provision are often the result of governance problems, such as accountability failures, rather than of technical or resourcerelated issues (World Bank 2004). 
Yet, there is little research that links these two trends, i.e. work on politics and governance issues underpinning the operations of small-scale informal private piped water providers. This article, drawing on exploratory field research in a large informal settlement at the urban fringe of New Delhi, attempts to fill this gap. Informal private providers are ubiquitous in such settlements and offer a service in the context of the absence of the state. Yet such provision is often problematic, as providers, out to recoup costs and generate profits rapidly (due to the high risks involved), exploit captive users and offer substandard service. One can characterise the starting situation as a vicious cycle of relationships between residents, informal piped network providers, politicians and the water authority, that traps communities into a situation of poor access and quality of service. The question then is: how can the vicious cycle be converted into a virtuous one, in which informal private water providers are legalised and regulated by the state to provide safe and affordable water at a desired level of service?

In-keeping with findings elsewhere, the research shows that while informal private providers fill a gap left by the formal public utility due to limited resources, capacity and the insecure tenure of the settlements, residents are often captive consumers with limited ability to influence service quality or price. However, the evolving trajectory of relationships between these stakeholders in the case examined here, suggests that the pathway to change may lie in the dynamics of how the relationships themselves evolve. While the particular processes through which this happens in this case are unique, they point to some key factors that can enable such a transition. We argue that two factors matter: (1) the nature of the service, in that certain forms of provision by small-scale independent providers, particularly piped water systems, are more conducive to triggering collective action, claimmaking and accountability demands on public utilities for better services; and (2) rising political awareness and competition, which can enable community groups to break out of clientelistic relationships with local politicians and facilitate direct engagement with public utilities.

This article is organised into seven sections. The section following this introduction explores the manner in which urban politics influences the delivery of basic services, and the operations of non-state providers. The next three sections present the case material. This is analysed in section 6, highlighting two factors that are key in moving towards more accountable relationships with the utilities and local politicians. We conclude with some observations.

\section{Non-state providers and collective action}

In many cities, the poor access services in lowincome settlements through the local political process (Coelho et al. 2011; Cross 1988). Often such relationships feature patronage or clientelistic politics, in which local politicians offer quasi-legal settlements incremental improvements in services, in return for electoral support. Although this is changing in some cities as institutions for direct participation of citizens in governance are developed (e.g. governance councils in Brazil or the Bhagidari programme in Delhi), by and large, the route for accessing services for the poor remains through political channels. Yet, very few studies explicitly examine how residents of low-income settlements engage with the political system to make claims on the state around water. Jha et al. (2007) highlight the role of local intermediaries - pradhans - in linking residents with elected politicians, aggregating demands and delivering support. Such local intermediaries and politicians have few incentives to provide the level of public services that residents desire - and are often willing to pay for - as that would weaken the hold they exert on such populations.

Coupled with this, service utilities in most developing countries have limited resources, capacity or interest in providing services to settlements that are often on precarious ground, both geographically and legally. As a result, such settlements are often served by informal nonstate water providers which operate on the margins of the law (Schaub-Jones 2008; Conan 2005; Kariuki and Schwartz 2005). As SchaubJones (2008) shows, these non-state small-scale providers are filling a gap where public water utilities have failed: they invest significant amounts in developing alternative systems despite the challenges; they are innovative both technically and operationally; and the potential pool of such entrepreneurs may be larger than many believe. Yet often, these informal providers offer services at high prices and uncertain quality. Consequently, several observers have 
called for greater engagement with such smallscale providers as a means to overcome the limitations of the utility-led model for extending water services for poor and underserved areas; and improving service levels offered by informal providers (WSP 2009; Schaub-Jones 2008; Sansom 2006; Njiru and Albu 2004). The desired scenario is one in which small-scale water providers carry out their operations under the scrutiny of the state, and consumers have access to high-quality services at reasonable prices, with strong grievance redressal systems built in.

However, the existing alignment of various stakeholders is not naturally conducive to delivering the desired change. Local politicians and leaders have few incentives to extend full services - either through utilities or non-state providers - to informal settlements. In fact, they often have significant financial stakes in the running of informal provision, either through direct ownership or through close family, financial or political ties. Public utilities are themselves overstretched and under-resourced; and dealing with informal settlements is seen as messy and 'unprofessional'. Finally, citizens, on their part, are trapped into unsatisfactory relationships with providers due to the lack of alternatives and, more importantly, the problems of collective action. Indeed, often the intermediaries and politicians are the ones who head neighbourhood associations. The case study reported below suggests a potential pathway for moving out of this impasse.

\section{The context}

In India, urban water supply is managed by public utilities. Most utilities are unable to provide water at adequate levels of service to the whole population. Over the years, there has been under-investment in infrastructure and poor management of existing assets and water resources, leading to acute water problems in many cities (Caseley 2003; Tata Consulting Services 2003). The poor bear the brunt of inadequate services, particularly as their ambiguous tenure status acts as a further disincentive for public utilities to extend services to areas inhabited by them. Under pressure, urban local governments sometimes provide water tankers or standpipes in illegal settlements; however, these offer erratic supply and are inadequate to meet demand. As a result, thousands of urban dwellers living in slums and illegal settlements get water from informal providers - water vendors or piped water suppliers (Angueletou-Marteau 2007; Llorente and Zerah 2003).

The government's approach to the issue of basic services in illegal settlements has tended to be determined by political expediency. Despite residents' continuous efforts, unauthorised settlements have been regularised in Delhi only twice: once in 1961, and again in 1977. Demands have been raised, and promises made at every election since, but with no long-term sustainable outcome. The provision of services by public utilities in such settlements had been restricted by the High Court, due to their ambiguous legal status. However, a series of rulings in 1994, 1998 and 2004, permitted the provision of electricity and water supply; roads and drains; and sewerage facilities, respectively, to these settlements, in order to improve degraded living conditions. In spite of this, implementation has been piecemeal and sluggish, as utilities have been reluctant to act, should such action be interpreted as an indication of de facto legalisation. Moreover, there is reluctance to invest in an area whose configuration in the long term is unclear. As a result, initiatives have been sporadic and politically driven. ${ }^{2}$

After continuous pressure from collective actors, citizen groups, the courts and the media, the government finally notified guidelines for the regularisation of such illegal settlements in 2008. The guidelines elaborate a number of steps that residents and public entities are to undertake, in order to legalise any settlement. ${ }^{3}$ Only after such steps are undertaken and approved, may an area be taken over by the public utility for provision of infrastructure in a planned and comprehensive manner.

Sangam Vihar is one such 'unauthorised' settlement at the southern periphery of Delhi, that could potentially access services, including water, through a process of regularlisation. ${ }^{4} \mathrm{It}$ currently houses an estimated 0.4-0.6 million inhabitants, and has existed for over 30 years (Dasgupta and Puri 2005). The present residents consist largely of low and low-middle-income households, comprising petty vendors, unskilled workers, small service providers, domestic help and low-level public sector employees. Yet, as we will see, the process of gaining access to services 
has been a complex one, involving collective action, petitioning of the water utility and appealing to local elected political representatives. Over the period spanning mid2007 to early 2008, we researched the trajectory of potable water in Sangam Vihar. The methodology followed was one of structured interviews, with both residents of Sangam Vihar and private providers. Although a format for the questionnaire was developed, the actual conversations were much broader, and covered several issues, inextricably linked with the provision of water services. In all, eight key residents were interviewed. Interviews with private providers were difficult to elicit, due to the perceived nature of their activities - four were interviewed. Most of the interactions, with both residents and providers, occurred in blocks $\mathrm{B}$ and $\mathrm{D}$ of the sprawling settlement. In addition, in both areas, members of the Residents' Welfare Associations (RWAs), mostly formed around issues of water and physical consolidation, were rich and valuable sources of information.

\section{Non-state providers of piped water, Sangam Vihar}

Because it is considered an 'unauthorised' settlement, the Delhi Jal Board (DJB, the public water utility) does not provide Sangam Vihar with a piped water supply. In the early years of its formation, the area was supplied through public hand pumps. Residents reported being satisfied with this arrangement, until increasing usage caused a lowering of groundwater levels, and water discharge from the hand pumps became erratic and unreliable. In response to this, a few households established private borewells. While these initially served only the households' needs, the owners soon started supplying water to neighbouring residents and households in the vicinity for a small payment. By 1985, seizing a clear opportunity, these entrepreneurs had established and extended borewell-based local piped water networks to service neighbourhoods/ households on a commercial basis.

To understand the political aspects, it is important to understand some technical aspects of the system. On average, a system consisting of a borewell, a pump and a distribution network of pipes may serve 150-200 households. Some, however, are larger and may cover up to 500 households. Entrepreneurs themselves are rarely involved in the day-to-day operation: they engage operators to run the systems. Water is pumped directly from the ground, into main distribution lines, which further branch out into secondary and branch lines laid through the streets being served. The operator manipulates a series of valves on each line to direct the water into a specific branch line. After households on the concerned branch line have drawn water, valves are adjusted to divert the water to the next line, and so forth until all the lines have been supplied. While the entrepreneur invests in establishing the system, households are responsible for establishing the connection from the branch line to their plot. The cost of this may vary, depending upon the distance of the plot from the nearest branch line. In addition to bearing the cost of connection, the households must also pay a one-time connection charge, and a fixed monthly fee for the water consumed.

Typically, the cost of connection averages US $\$ 30$, but may be as high as US $\$ 70$, when the distance to the providers' pipeline is substantial. The connection charge was US $\$ 20$ at the time, and the monthly fee varied from US\$6-10.5 This seemed loosely related to consumption - most houses filled a 500 litre capacity overhead tank, and households with larger tanks, or tenants, were charged more. All the operators interviewed claimed there was a 'special consideration' to poorer households. In contrast, the average monthly bill of a typical middle-income household being supplied by the public utility, averages US\$6-8.

Of significance is that the geographic area of operation is not exclusive to any one entrepreneur. More than one entrepreneur often establish main, secondary and branch lines through the same streets. Thus, in theory, households may exercise a choice among operators, at least at the initial stage. Once connected, however, the options for change become limited, due to the expense incurred in changing the household connection from one operator's line to another. Thus, in practice, hardly any households change their service providers while they are in operation. ${ }^{6}$

These arrangements for distribution of water do not have formal recognition or legal sanction. There is no monitoring by the utility, or licensing arrangement to ensure quality of water, level of service and terms of operation. In effect, the operations are deemed illegal, and consequently, 
are under continuous risk of being detected and terminated. Typically, the entrepreneurs establishing the systems are well linked to local politicians or influential residents - alleviating the risk, to a certain extent. ${ }^{7}$ This has a significant impact on the investments incurred and the nature and level of service that is provided.

Because of the risks, the operator's key interest is to recover the costs of establishment in the shortest period of time. Since households pay on a monthly basis, rather than on the basis of water consumption, the attempt is to increase the customer base, and hence revenues, in order to achieve this. ${ }^{8}$ The system, however, has a limited capacity to deliver; water must be made available in each branch line for a minimum period each day, so that households have sufficient time to fill their ground level storage units. ${ }^{9}$ Increasing the customer base by adding a small branch line, or connecting more households to an existing branch line, reduces the amount of time that each household has to draw upon the water. As a result, households that had access to water for a few hours each day when they were initially connected to a network, reported being able to draw water for barely 15-20 minutes in a day as the operator increased the number of households being supplied. Furthermore, the supply of water to branch lines could be reduced to alternate days, in order to accommodate larger numbers of households.

The increase in the number of connections implies longer operating and pumping hours - at times, pumps are operated for up to 18 hours a day in order to supply all households. Despite this, systems are manned by single operators, and none reported having a standby pump. It is not infrequent for pumps to overheat and malfunction, especially during the hot summer months. This was reported to occur almost 3-4 times every summer, disrupting supply for up to three days. Additionally, long hours of operation, coupled with unpredictable electricity outages in the area, with no provision for standby electricity, make it difficult to establish a reliable timetable for supply. As a result, water is made available to households at erratic timings: as one resident put it, 'at any time of day or night'. ${ }^{10}$

The need to maximise revenues in the shortest period of time also leads to charges being increased suddenly, or connections being cut arbitrarily. If a new household is willing to bear higher charges, an existing connection may be discontinued suddenly, in order to accommodate the new connection. ${ }^{11}$ Since all operators in the area follow similar practices regarding supply and billing, residents have few alternatives.

\section{Petitioning for a public water supply}

Erratic service, steep charges and the increasing lack of response, over time, to households' concerns on the part of private operators led to the formation of resident groups in Sangam Vihar to actively petition for public provision of water, since 2001..$^{12}$ This petitioning was fuelled by a growing public perception that water supply was the government's responsibility and that citizens have a right to a drinking water supply. Implicit in this was the assumption that public provision should be subsidised or provided at a lower cost than that presently available through the private providers. As one resident put it, 'if so many families are settled here, how can government not provide water for them? ${ }^{\text {13 }}$ Yet, numerous efforts to plead with the DJB proved futile. ${ }^{14}$ As one resident put it 'joote poore ghis jayenge, par milega kuch nahin' ('the soles of our shoes will wear out, but we will get nothing'). ${ }^{15}$ Moreover, while the RWAs were aware that the DJB, as the water utility, was responsible for providing them with water, they did not know the processes to be followed to legally procure a supply. ${ }^{16}$

Discouraged by the lack of response from the DJB, in 2006 the resident groups approached the areas elected representatives: Members of the (State) Legislative Assembly (MLAs). By now, there was a perception that public services could be procured through the MLA. The two MLAs approached, both of whom were from opposition political parties at the time, supported the groups and followed-up by writing to the DJB and leading protests and demonstrations to the DJB offices. This activity met with some success: the first tubewell was established in 2006 and three more were established in 2007. The capital costs for the wells were met by the MLA's area development funds and the electricity connection was paid for by the public utility. Public standpoints were provided at the wells, but no further work to enable household connectivity was undertaken.

However, residents were unhappy with having to access water from a public standpoint - having 
become used to piped household supply, despite the poor service levels. Consequently, resident groups collectively undertook the work of planning and implementing a distribution system from the public standpoint enabling each household to connect individually to the piped system. Money was collected to pay for the distribution lines, while individual household connections were the household's responsibility. ${ }^{17}$ The RWA organised the operation and maintenance of the system, typically in the same manner as the private providers. Local youth are employed to open valves and inform households of the availability of water in their lines.

Residents report greater satisfaction with this arrangement, as there is an agreed-to schedule for supply, and costs are not increased arbitrarily since the collective works as a cooperative. A monthly contribution of US $\$ 1$ is collected by the RWA from each beneficiary household, to cover operations and maintenance costs for the pump operator, and minor repairs to the network pipes. $^{18}$

At least one private operator, among those interviewed, reported having been put out of business by the establishment of a public tubewell resulting from the residents' collective action. RWAs confirmed that private operators had initially been sceptical that their demands would be heeded to - and had had little interest in negotiating with residents to improve services to avoid being made redundant. Existing private providers thus have no role in the new arrangements, and their political patrons belonging to the ruling dispensation in the state - also stand sidelined.

While both the DJB and the area MLA are well aware of these activities of extending and managing piped networks by the RWAs, they turn a blind eye to them. The operations of this system are entirely 'unofficial' and the DJB has made it clear that its involvement terminates at the establishment of the deep borewell: it will entertain no requests or complaints related to the system thereafter. This is because the extension of full water supply services to Sangam Vihar by the DJB is contingent upon its regularisation through the process indicated in the guidelines notified in 2008. ${ }^{19}$

The arrangement that the RWAs are putting in place - tubewells installed by DJB and distribution lines operated and maintained by its own staff - could potentially lead to greater independence from local political representatives, provided that it is recognised and accepted by the DJB. This is not yet the case however, leaving the window open for politicians to intervene. Any illegal operation is in the local politician's interest, who will be unwilling to allow a change towards a more transparent and formal regime that will effectively reduce his influence.

Officials within the DJB are well aware that current arrangements are similar to the ones under the private operators. But where the private operators were recouping costs and reaping profits by charging high rates, the current actual costs of operating the system are not being reflected in the charges levied by the resident groups. The utility receives no payments under the present arrangements. Moreover, the utility bears the costs of electricity for the tubewells. One view was that the arrangement could be made more sustainable in the long term, if residents were to meet the cost of the service, including electricity, maintenance and manpower, under a system operator selected and overseen by the DJB. ${ }^{20}$ The dilemma faced, however, is how to ensure that the process of selection is fair and transparent - and not captured by vested interests.

Should the DJB agree to the option of private provision, entailing no investment from its side, and agree to play a critical (but minimal) regulatory role, the provision of piped water supply can be de-linked from the settlement's status, particularly as the process of regularisation is likely to be long drawn out. The agreement with the private operator could be drawn up for a limited number of years, and expressly de-linked from any rights of occupation. ${ }^{21}$

\section{Enabling factors}

The trajectory presented above suggests a potential path through which the poor quality service trap faced by residents could be transformed, resulting in better services, a responsive DJB and potential regulation of private providers. While widespread discontent with the services of private providers was the key motivating factor in this shift, we argue that user mobilisation was greatly facilitated by two specific factors, outlined below. 


\subsection{Nature of service}

Informal piped networks, we argue, offer greater potential for collective action. Unlike public standpipes or informal water vendors, piped networks enable relatively clear boundaries of user households associated with particular piped systems (or even branches of systems in the case of large systems). ${ }^{22}$ Such a natural clarification of boundaries of beneficiaries supports collective action because the physical configuration encourages small groups in which free-riding is prevented by the nature of service itself (Olsen 1971). These groups are bound by a shared sense of outrage and dissatisfaction with inadequate water supply.

Moreover, piped water systems require substantial investments by the households prior to accessing water. Thus, households acquire a stake in the system operations, creating incentives to demand formalisation; or alignment with and provisioning through a formal recognised system of delivery. Within the existing operations, households also felt a right to demand (and be provided) adequate levels of service, by virtue of bearing the cost of service. Payments introduce the right to accountability. This is unlike services derived from water vendors, where investments are not (directly) made by households - the stakes are much lower, and erratic or poor services may not generate the motivational force for mobilisation and claim making.

\subsection{Political awareness and competition}

The collective action enabled by the nature of piped systems was enhanced by increased political awareness among residents. The profile of residents subscribing to piped water services is also a factor: most of these households are not at the bottom of the ladder, but very much in the process of consolidating their status and habitat in the city. ${ }^{23}$ Their expectations of convenience in service delivery are not low, all the more so having experienced household access through the informal providers. In addition, greater penetration of the media has made residents aware of the larger political changes in the country, including the move towards rights-based approaches. They have become aware of their rights, and of the responsibility of public utilities to meet their needs. This provides legitimacy and conviction to their demands, as well as the process of petitioning.
Political competition at the local level has supported these shifts. The private providers in Sangam Vihar are politically well linked. The local politician in power has a stake in the business of the private operator, and is unlikely to favour any arrangement that disturbs this. Only with the rise of political competition at the local level were resident groups able to use political influence to reach the public utility, as opposition leaders have few vested interests in existing arrangements and high incentives to break incumbent political bases.

However, the extent of success that was achieved in Sangam Vihar was limited to the establishment of public tubewells - which entailed access to supply within the established framework. Household level connectivity was extended entirely through the efforts of the RWA. Effectively, claim-making did not lead to longer-term institutional reforms to facilitate provision of water at the household level. And in fact, current arrangements have a limited possibility of meeting the needs of the large population, as groundwater supply throughout the city is under threat.

\section{Conclusions}

Observers of this case might view it as one in which private providers offer poor water access and quality, and profiteer in collusion with local politicians at the expense of the poor. We suggest, however, that the very existence of such providers creates a potential pathway through which residents can access public services in the long term. Through a gradual shift in the incentives all stakeholders face - residents, providers, politicians and the water utility there is an opportunity to shift the low-level equilibrium towards better engagement, regulation and service provision.

Not all contexts lend themselves to such a shift. This case suggests that piped water systems, combined with political awareness and competition, are more likely to enable residents to tip the balance towards more accountable, responsive systems. Key steps in this process involve (a) heightening resident's stakes in a formal system, by virtue of the investment required by the household; (b) generating demand for accountability through levy of user charges; (c) the formation of geographically welldefined groups of households with a shared sense 
of dissatisfaction and purpose; (d) rising resident awareness of rights, and expectations of service delivery through public utilities; and (e) political competition leading to a break with past patronage relationships. Through such a process, informal provisioning may well represent an effective stepping stone to fully fledged, formal provision of services by public utilities.

The research shows how initial attempts of residents to break out of the dependence on informal providers and gain direct access to the public water supply provided by the water utility were not successful. Later, when residents approached local elected politicians who used their influence and budgetary resources, they

\section{Notes}

* The research reported here was partly supported by the DFID-funded Centre for the Future State at IDS. We are grateful for comments by participants at the Liquid Dynamics II Symposium held at IDS, 21-23 March 2011 and an anonymous reviewer.

1 It is well recognised that small-scale private providers have the background, social skills, flexibility and ability to customise operations in order to effectively service the particular and varied needs of the poor (Schaub-Jones 2008).

2 Noting the situation, the Delhi High Court, as well as the Supreme Court of India, have repeatedly directed the state to develop a policy for regularisation of illegal settlements, going so far as to record that 'the result of not taking decision is resulting in corruption (i.e. rent seeking) at various levels'. CWP No 4771/1993 entitled: Common Cause (Regd.) Society vs Union of India.

3 Including drawing up a plan of the area; earmarking plots for the provision of facilities and payment of development charges.

4 Such 'unauthorised' settlements are illegal because land was subdivided and sold without the requisite planning permissions.

5 Using an average rate of US\$1 = INR 50.

6 It is not uncommon for borewells to run dry. In this situation, households are reimbursed the connection charge and have no option but to change service providers.

7 For example, the original owners of the land, many of whom still reside in Sangam Vihar and may have been directly involved in the subdivision and sale of the land. had limited success with the utility extending standpipes to the settlement. However, as we show, the price for such political mediation is the establishment of a patron-client relationship between politicians and residents. In both situations, residents have limited abilities to hold the informal provider or the local politician accountable. Establishing a more direct relationship of entitlement between residents and the water utility by legalising and regulating informal providers and incorporating them into public systems, could be a more promising way of both ensuring sustainability of water provision, and improving the governance of urban water services.

8 Installing meters to monitor usage would be perceived as an additional, unnecessary cost. As is described later, water consumption is limited through other strategies.

9 In order to ensure that pressure is sufficient, households are provided with water in a staggered or sequential manner. Most households will use pumps to draw water into their storage unit. A few depend on gravity flow. Storage units typically have a capacity of 500 litres.

10 Personal interview, resident; D-Block, Sangam Vihar, August 2007.

11 There is often a marked variation in charges for the same level of service.

12 While resident groups may take up other issues, the main purpose for their formation was stated to be to petition for water. Groups are commonly formed around streets or 'gullies', but may include several streets to encompass a locality.

13 Personal interview, General Secretary, B-Block RWA, Sangam Vihar, November 2007.

14 The elected ward councillors (representatives to the Municipal Corporation of Delhi) were similarly ineffective.

15 Personal interview, President, Shri Ganesh Welfare Society, D-Block, Sangam Vihar, December 2007.

16 For example, the DJB was unwilling to make any provisions until the area's electricity supply was formalised. This was achieved in 2005, again as a result of the RWA's efforts.

17 Typically, each household's contribution was $\mathrm{US} \$ 30(\mathrm{US} \$ 1=\mathrm{INR} 50)$.

18 This is a fraction of the monthly charge (US\$6-10), which was earlier being paid to private operators. 
19 The process itself is being taken forward very slowly, and the feasibility of achieving the objective is not very clear.

20 Personal interview, DJB official, February 2010.

21 This approach has been adopted successfully in the Slum Networking Programme in Ahmedabad, India. Land-owning agencies have provided 'No Objection Certificates' (NoCs) to settlements on their sites for limited periods of time, in order to enable the provision of services to the inhabitants in the

\section{References}

Angueletou-Marteau, A. (2007) Informal Water Suppliers Meeting Water Needs in the Peri-Urban Areas of Mumbai, Research Paper 7, Grenoble: Laboratoire d'Economie de la Production et de l'Integration Internationale, http://halshs.archives-ouvertes.fr/docs/00/26/ 08/17/PDF/CR7_Angueletou-2007.pdf (accessed 7 January 2012)

Bakker, K. (2008) 'The Ambiguity of Community: Debating Alternatives to Private Sector Provision of Urban Water Supply', Water Alternatives 1.1: 236-52

Batley, R. (2006) 'Engaged or Divorced? Crossservice Findings on Government Relations with Non-state Service Providers', Public Administration and Development 26.3: 141-51

Batley, R. (2004) 'The Politics of Service Delivery Reform', Development and Change 35: 31-56

Caseley, J. (2003) Blocked Drains and Open Minds Multiple Accountability Relationships and Improved Service Delivery Performance in an Indian City, IDS Working Paper 211, Brighton: IDS

Castro, J.E. (2004) 'Urban Water and the Politics of Citizenship: The Case of the Mexico City Metropolitan Area in the 1980s and 1990s', Environment and Urbanization 36: 327-46

Chaplin, S.E. (2011) 'Indian Cities, Sanitation and the State: Politics and the Failure to Provide', Environment and Urbanization 23.1: 57-70

Coelho, K.; Kamath, L. and Vijaybaskar, M. (2011) Infrastructures of Consent: Interrogating Citizen Participation Mandates in Indian Urban Governance, IDS Working Paper 362, Brighton: IDS

Collignon, B. and Vézina, M. (2000) Independent Water and Sanitation Providers in African Cities, Water and Sanitation Program, Washington DC: World Bank

Conan, H. (2005) Small Piped Water Networks: Helping Local Entrepreneurs to Invest, Manila: Asian Development Bank interim. The NoCs confer no rights to the residents with respect to the land, but facilitate financing of infrastructure in an environment of relative, although limited, security.

22 The importance of technology and network effects of piped systems on governance and collective action has been noted by others (e.g. Watson 1995; Joshi and Moore 1997).

23 However, some households were well below the poverty line.

Cross, J. (1988) Informal Politics: Street Vendors and the State in Mexico City, Stanford: Stanford University Press

Dasgupta, P. and Puri, S. (2005) 'Private Provision of Public Services in Unauthorised Colonies - A Case Study of Sangam Vihar', unpublished Working Paper, New Delhi: Genter for Civil Society

Delhi Jal Board (2011) DJB website, www.delhijalboard.nic.in (accessed 25 July 2011)

Jha, S.; Rao, V. and Woolcock, M. (2007) 'Governance in the Gullies: Democratic Responsiveness, and Leadership in Delhi's Slums', World Development 35.2: 230-46

Joshi, A. and Moore, M. (1997) 'Ten Tales of Two Cities: Institutions, Politics and Technology in the Reform of Urban Water Supply in Vietnam', unpublished paper, Brighton: IDS

Kariuki, M. and Schwartz, J. (2005) Small-Scale Providers of Water Supply and Electricity, World Bank Policy Research Working Paper 3727, Washington DC: World Bank

Llorente, M. and Zerah, M.H. (2003) 'The Urban Water Sector: Formal Versus Informal Suppliers in India', Urban India, XXII.1, Delhi: National Institute of Urban Affairs

McGranahan, G. and Owen, D.L. (2006) Local Water Companies and the Urban Poor, Human Settlements Discussion Paper Series, London: International Institute for Environment and Development (IIED)

Njiru, C. and Albu, M. (2004) 'Improving Access to Water through Support to Small WaterProviding Enterprises', Small Enterprise Development 15.2

Olsen, M. (1971) The Logic of Collective Action, Cambridge MA: Harvard University Press Rose, P. (2006) 'Collaborating in Education for All? Experiences of Government Support for Non-state Provision of Basic Education in South Asia and Sub-Saharan Africa', Public Administration and Development 26.3: 219-29 
Sansom, K. (2006) Supporting Non-State Providers of Water Services, paper for DFID Policy Division, Loughborough: WELL Resource Centre

Schaub-Jones, D. (2008) 'Harnessing Entrepreneurship in the Water Sector: Expanding Water Services through Independent Network Operators', Waterlines 27.4

Tata Consulting Services (2003) Study on Rationalisation of Pattern of Distribution of Water for Delhi, New Delhi: TCG

United Nations (1992) The Dublin Statement on Water and Sustainable Development, International Conference on Water and the Environment, Dublin, 31 January 1992, www.ielrc.org/content/ e9209.pdf (accessed 1 December 2011)

United Nations (1990) New Delhi Statement, Global Consultation on Safe Water and Sanitation, 1990, www.ielrc.org/content/e9005.pdf (accessed 1 December 2011)

van Dijk, M.P. (2008) 'Role of Small-Scale Independent Providers in Water and Sanitation', International Journal of Water 4.3-4: 275-89

Watson, G. (1995) Good Sewers Cheap? AgencyCustomer Interactions in Low-Cost Urban Sanitation in Brazil, Washington DC: World Bank

World Bank (2004) Making Services Work for Poor People, World Development Report, Washington DC: World Bank WSP (2009) Improving Water Utility Services Through Delegated Management - Lessons from the Utility and Small-Scale Providers in Kisumu, Kenya, Field Note, Water and Sanitation Program (WSP), May, New Delhi: WSP 